\title{
Effect of Media on Children Behaviour: Media Psychological Perspective
}

\author{
Mr. Rajput Kiransinh Natwarsinh*
}

\begin{abstract}
:
There is both Negative and positive effect of Media on Children Behaviour. The first issue of the media's effects on children is violence in the media. By far the greatest amount of psychological research on the media has concerned the impact of televised violence and violence contained within video games on children and concluded that exposure to Media and video game violence leads to increased aggression, an effect that has been demonstrated both as a short term consequence and longer-term effect of excessive exposure. Parents commonly express concern over advertising directed at children, perceiving it as a source of conflict with their children who demand advertised products that parents may feel are inappropriate, and also fearing that it may lead them to adopt overly materialistic values. Media play Importance role in child socialization processes and it play role to teach child cultural values and beliefs. Media also play role in Children education and their awareness about Global issues. Parental Mediation play Importance role to Increase Positive effect of media on children and reduce Negative effect of Media on children.
\end{abstract}

Key Words: Media Violence, Aggression, Adverting, Child Socialization and Parental Mediation.

\section{INTRODUCTION:}

Media representations are not simply a mirror of society but rather that they are highly selective and constructed portrayals. It is the capacity of these portrayals to shape and frame our perception of the world which is under consideration here. The first two issues which are reviewed concern the media's effects on children. The first of these is violence in the media. By far the greatest amount of psychological research on the media has concerned the impact of televised violence and violence contained within video games on children. Since literally thousands of studies have been conducted, we attempt to make sense of this vast literature by drawing together the conclusions made by existing authoritative reviews of the literature. The complexity of the questions involved in this area make it difficult to reach clear-cut conclusions, but there is reasonable consensus on some central issues. For instance, it is generally agreed that prolonged exposure to media violence is one of the many interacting factors which lead to children being more likely to display aggressive behaviour in the long term. It is also agreed that the social context is important in determining the effects of exposure to violent media; e.g., if an adult helps the child interpret and critique the viewed material, the negative effects are lessened. Later research on violent video games has largely supported these effects of violent media, showing that exposure to video game violence leads to increased aggression, an effect that has been demonstrated both as a short-term consequence and longer-term effect of excessive exposure.

*Teaching Assistant, Department of Psychology, Faculty of Education and Psychology, The M.S. University of Baroda, Vadodara 
The second area reviewed concerns advertising. Parents commonly express concern over advertising directed at children, perceiving it as a source of conflict with their children who demand advertised products that parents may feel are inappropriate, and also fearing that it may lead them to adopt overly materialistic values. We review the literature on whether and when children can distinguish advertising from other forms of programming, and the extent to which it affects their desire for products and their buying behaviour. It appears that, although very young children can discriminate advertisements from programs, it is not until school age that children are aware of the specifically persuasive intent of advertising. It also appears that advertisements can affect product choices, although as with most media effects, there is a range of moderating factors. The research on other concerns, such as the potential of advertising of unhealthy food products to contribute to obesity, is also reviewed. It is concluded that, despite gaps in the research literature, there is evidence that children are affected by advertisements and that regulation of the nature and timing of advertisements directed at children is warranted.

Nevertheless, Comstock and Scharrer (1999) argued that meta-analyses of this work offer "incontestable documentation that empirically there is a positive association between exposure to Television violence and antisocial behaviour." This may be, although that association is tempered by many other variables that are not consistently controlled in all studies. Paik and Comstock (1994), except that most studies have noted a relationship between heavy viewing of violent television and viewing of all television. Nevertheless, Comstock and Scharrer (1999) argued that meta-analyses of this work offer "incontestable documentation that empirically there is a positive association between exposure to Television violence and antisocial behaviour." This may be, although that association is tempered by many other variables that are not consistently controlled in all studies. Paik and Comstock (1994), except that most studies have noted a relationship between heavy viewing of violent television and viewing of all television.

\section{THEORETICAL EXPLANATIONS FOR THE IMPACT OF THE MEDIA ON VIOLENCE}

Media are clearly not the only, nor the most important, contributors to human social behaviour, but are unquestionably an important source of social influence. Although the relationship between exposure and effects is neither simple nor direct, more than 40 years of research has indicated that television, video games, and internet content can and do influence our feelings, attitudes and behaviours ( Anderson et al., 2010; Anderson \& Bushman, 2002). In both the longand the short-term, our experience of media images contributes in significant ways to how we think, act, and feel, and to our broader beliefs about the world and social reality. The imitative modelling of media effects was studied in a series of experiments by Albert Bandura in the 1960s, widely known as the "Bobo doll" studies due to the use of an inflatable plastic doll that children were observed to strike more frequently after watching an adult perform the same activity on video (Bandura et al., 1963). Nevertheless, Comstock and Scharrer (1999) argued that meta-analyses of this work offer "incontestable documentation that empirically there is a positive association between exposure to Television violence and antisocial behaviour." This may be, although that association is tempered by many other variables that are not consistently controlled in all studies. Paik and Comstock (1994), except that most studies have noted a relationship between heavy viewing of violent television and viewing of all television.

A typical excitation transfer experiment involves participants viewing films, or short clips from films, in different conditions; usually there is a control condition in which the film is neutral, or nonviolent, and at least one experimental condition in which the film is violent. Participants are 
then placed in a situation in which they can display aggression or hostility toward a stimulus figure (typically, a confederate of the experimenter). Initial excitation transfer studies (Zillmann, 1971) used Milgram's classic electric shock paradigm, where aggression is measured by the intensity of (simulated) shocks given by the participant to an actor masquerading as a participant in the context of a conditional learning task. Usually, participants in the violent condition display higher levels of physiological arousal during the viewing episode than do those in the control condition. They also display significantly higher levels of aggression in the subsequent task, particularly when anger or frustration has been induced (Freedman, 1986). A typical excitation transfer experiment involves participants viewing films, or short clips from films, in different conditions; usually there is a control condition in which the film is neutral, or nonviolent, and at least one experimental condition in which the film is violent. Participants are then placed in a situation in which they can display aggression or hostility toward a stimulus figure (typically, a confederate of the experimenter). Initial excitation transfer studies (e.g., Zillmann, 1971) used Milgram's classic electric shock paradigm, where aggression is measured by the intensity of (simulated) shocks given by the participant to an actor masquerading as a participant in the context of a conditional learning task. Usually, participants in the violent condition display higher levels of physiological arousal during the viewing episode than do those in the control condition. They also display significantly higher levels of aggression in the subsequent task, particularly when anger or frustration has been induced (Freedman, 1986).

A number of theoretical models and approaches help to explain the complex links between media exposure and its effects. Historically, many of these have been concerned principally with the impact of TV violence on children. However more recently, generalised theories of the ways in which media influence cognition, affect, and behaviour have begun to emerge. Theoretical explanations have increasingly emphasised a range of contextual factors including features of the message, the viewer, and the broader social setting that influence audience reactions. In particular, contemporary theories have argued for a more 'receiver-centred' approach in which the viewer is seen as an active participant who constructs meaning from viewing. Increasingly, such accounts accept that selectivity and intentional choice, attention and involvement are forms of activity that facilitate media effects (Kim \& Rubin, 1997). Thus, psychological models of media influence predict variability between individuals in their effects, whilst still allowing for common patterns to emerge.

\section{CULTIVATION THEORY:}

One major theoretical approach, cultivation theory (Gerbner, Gross, Morgan, \& Signorielli 1994; Signorielli \& Morgan, 1990), is an attempt to understand and explain the influence of television as a source of broadly shared images and messages about the world and its people. It concentrates on the enduring and common consequences of growing up and living with television. Gerbner and his colleagues argue that, to the extent that television dominates children's sources of entertainment and information, continued cumulative exposure to its messages is likely to reiterate, confirm and nourish--that is, cultivate--the beliefs, agenda, values, and perspectives that it portrays (Signorielli \& Morgan, 1990). From this standpoint, television is a powerful cultural force that produces stable, resistant-to-change and widely shared assumptions, images, values and concepts. It cultivates a mainstream view of what issues are important (e.g., crime, the environment, body image) and what the world is like (e.g., dangerous). Moreover, it cultivates specific value systems, ideologies, and perspectives (e.g., materialism, consumerism, ethnocentrism, individualism, capitalism, social responsibility). 


\section{SOCIAL LEARNING THEORY AND SOCIAL-COGNITIVE ACCOUNTS:}

While cultivation theory tries to explain media effects on society in general, other psychological theories have been concerned with understanding the long- and short-term effects of media exposure, especially televised violence, on the attitudes and behaviours of individuals, particularly children.

Perhaps the most widely accepted account of the way in which televised content affects the attitudes and behaviours of the developing child is Bandura's social learning theory (1971, 1986). Bandura argued that people learn behavioural responses such as aggression either by direct experience in which their own aggressive behaviour is reinforced or by observing that such behaviour brings rewards to others (that is, through vicarious reinforcement). Further, media characters are -along with parents, peers and others - the sources that provide the text for modelling specific attitudes and behaviour, and attitudes and behaviours that are learned at a young age through habitual exposure to such models are argued to be relatively resistant to change. For instance, through observing the behaviour of televised models, children come to learn which attitudes and behaviours are accepted and rewarded and which are punished, and they will be motivated to imitate media models whose behaviour is rewarded.

\section{SOCIAL-DEVELOPMENTAL MODEL:}

Both modelling and cognitive priming accounts are essentially one-directional. Media content is believed to influence audience members. The more integrative social developmental model (Huesmann \& Miller, 1994) describes the cognitive basis of learned patterns of social behaviour and places greater emphasis on the reciprocal relationship between the viewer and the medium.

\section{DESENSITIZATION:}

In understanding the effects of media content on attitudes and behaviour-and particularly portrayals of violence and aggression-an additional theoretical approach has drawn attention to the potential role of emotion. According to the desensitisation hypothesis, repeated viewing of violence leads to a reduction in emotional responsiveness to violence on the screen and to an increased acceptance of violence in real life. For instance, although young children may initially exhibit intense fright and fear reactions to violent program content (Cantor, 1994), they may become increasingly accustomed to violence in programs and may desire increasingly violent content as they become habituated or desensitised (Drabman \& Thomas, 1974). Prolonged viewing of violence by children and adults alike may lead to a reduction in emotional responsiveness to real world violence, to an increased acceptance of violence in everyday life, and to the development of callous attitudes toward victims of violence.

\section{MODELS OF PERSUASION:}

The theoretical models above seek to explain the effects of entertainment and current affairs programming on viewers' feelings, thoughts and behaviours. Some literature has also concentrated on the effects of televised messages or media campaigns that are explicitly intended to alter attitudes and behaviour. In some cases, the intentions of television commercials can be regarded as socially desirable, such as those promoting healthy lifestyles. However, the intentions and likely outcomes of others, like much product advertising, are more debatable
(C) 2014 www.ijip.in
July-September 2014
$129 \mid \mathrm{P}$ a g e 
Despite these complexities, most reviewers also conclude that convergent generalisations do emerge with sufficient consistency to justify attention by parents, educators, legislators and the industry. Such effects can be summarised as follows: children who watch violence on television or are exposed to violence within video games have a higher likelihood of behaving aggressively in the short term; persistent consumption of violent media is related to an increased likelihood of behaving aggressively in the long term and in some cases this may include serious criminal violence; consumption of violent media is only one of a number of factors which contribute to the tendency to violence and aggression, and its contribution is small to moderate (as is the case for all other measured antecedents of violence); some children enjoy, and develop an appetite for, viewing violent material; viewing violence on television leads to immediate distress and fear in many children; many children retain longer-term recurrent disturbing memories from viewed violence; high levels of violence viewing are associated with heightened general fearfulness about life; these effects are consistent across Western and Eastern cultures; beside increased aggression and fearfulness effects include decreased empathy, and reduced prosociality, continual exposure to media violence increases the likelihood that children will be desensitised to real violence; age and gender are important influences on the nature of the effects; boys tend to be more directly affected than girls; negative effects of violent media are more consistently observed in younger than older children; most children's preferences are for exciting and humorous media, and violence is generally unwelcome except for its association with high levels of action; and There is widespread community concern, particularly amongst parents and teachers, based in part on direct experience of the effects of violent media on with children.

It is now widely acknowledged that the media are not a simple mirror of society, reflecting the world out there.' If this were so, journalists would simply need to point their camera or recorder in a random direction and let it roll. Rather, active decisions are taken at every stage of the process of producing and transmitting media material, regarding what should be included and what should be omitted, and how and when the content should be presented. It can therefore be argued that the media have the potential to play an active part in shaping and framing our perception of the world, and indeed in affecting the nature of that world.

The role of media in modern life is indispensable, providing information, education and entertainment. It is not our intention to review the nature or extent of these positive influences. Rather, the focus of this paper is on potential negative impacts. Debate has raged about the nature and the extent of the negative impact of some aspects of the media on individuals' values, beliefs, attitudes and behaviours, and on society in general. Further, there is increasing concern over the role of the media in affecting the course of public events, such as international disputes and criminal court cases. At the same time, debate reflects the ongoing struggle to find the appropriate balance between control of media (with censorship as the extreme form of control) and rights to freedom of expression and of choice.

Zillmann and Bryant (1975) examined children at two stages of moral development in a study of empathic responses to a televised fairy tale. Wiegman et al. (1992) found a 0.9 correlation between the amount of anti- and pro-social TV watched. Davis (1983) found that children who scored highly on an empathy scale tended to prefer pro-social Programmes. Media help for children education and provide knowledge. Whether or not media produce the psychological effects claimed by many social scientists, there is no doubt that they are invaluable means of communicating information. Periodically, state agencies as well as private businesses have harnessed the informational power of media in an attempt to promote desirable behaviour, such
(C) 2014 www.ijip.in
July-September 2014
$130 \mid \mathrm{P}$ a g e 
The International Journal of Indian Psychology: Volume: 01 | Issue: 04 No. 2 | ISSN 2348-5396

as road safety or care with handling fireworks. Media have also played an important role in the communication of health messages, including worldwide publicity about HIV/AIDS ( Johnson, Flora, \& Rimal, 1997), smoking cessation programmes (Korhonen, Uutela, Korhonen, \& Puska, 1998), and warnings about skin cancer risk from sunbathing (Buller, Borland, \& Burgoon, 1998).

In many parts of the world, information about social issues is embedded within popular drama. Pro-social soaps (also referred to as "entertainment- education" media) are hugely popular in parts of Asia, Africa, and Latin America (Sherry, 1998; Singhal \& Rogers, 1999). These soaps follow the same broad structure as do soaps in Europe and North America, except that the storylines are explicitly pro-social, featuring issues ranging from local subjects (e.g., dowry in India, or agricultural information in Africa), to health issues (e.g., HIV prevention), to global issues (e.g., environmentalism). Even in the West, soaps often feature storylines that are intended to educate as much as entertain.

\section{CHILDREN'S SOCIALISATION THROUGH MEDIA}

If television might aid in the development of abstract cognitive structures (or narrative scripts), it may also teach children more directly about how to behave and respond in social situations. We cannot necessarily be complacent about children's media socialisation. Nevertheless, it could be argued that socialisation involves much more than simply copying behaviour viewed on screen, especially when the behaviour is strikingly inappropriate (as in cartoons or obvious fantasy shows like Superman). One of the most interesting, although under researched, questions about children and media concerns the way in which children come to identify media characters as analogous to people they know in real life. It may be supposed that such awareness develops in tandem with their real-life person knowledge. Bretherton and Beeghly (1982) found that children as young as 28 months were able to offer descriptive terms about real people based on personality traits such as "nice," "bad," "naughty," and so on. The development of more complex character judgments is the subject of a wide literature on childhood cognitive and social development (Yuill, 1992). Some limited research has been conducted on children's use of trait terms to describe media figures. Reeves and Greenberg (1977) and Reeves and Lometti (1979) used multidimensional scaling techniques to show how children from 7 to 11 years of age evaluate characters on the basis of typical human personality dimensions, but it is not known at what stage, and how, children come to equate the huge variety of anthropomorphic and human figures on television with the people around them in real life, and attribute consistent behavioural patterns and personality traits to them. Bearison, Bain, and Daniele (1982) examined developmental changes in children's understanding of people on television with reference to Piaget's theory of cognitive development. For Piaget, the key concept was perspective. Young children are largely egocentric because they do not consider that others might see the world differently; this was famously demonstrated using a model of three mountains and a doll placed on the side of the model opposite from the child. When children under 5 were asked to say what the doll was looking at, they overwhelmingly chose their own visual perspective; it was not until later that they appreciated that the doll might have a different perspective (Piaget \& Inhelder, 1969). Bearison et al. applied this theory to children's perspective of television characters. They showed a short clip from a daytime television drama to 5- and 6-year-olds, 7-through 10-yearolds, and 11- through 14-year-olds. These age groups corresponded roughly to Piaget's three key stages: preoperational (egocentric), concrete operational (reasoning based only on personal experience), and formal operational (ability to reason using abstract premises). As predicted, the
(C) 2014 www.ijip.in
July-September 2014
$131 \mid \mathrm{P}$ a g e 
preoperational children were only able to describe the physical settings and superficial aspects of interpersonal behaviour, whereas children at the concrete operational stage were able to go beyond the appearance of social interaction and actually make some inferences regarding characters' thoughts and feelings, and how these helped to shape the interaction. Similar findings were also obtained in a study by Hoffner and Cantor (1985). The Bearison et al. study could be criticised on a number of grounds, largely because the material used in the film seems to be wholly inappropriate for child participants, dealing largely with adult relationships. It may not be surprising that younger children were unable to follow the subtle psychological complexities of the plot. Furthermore, there were substantial differences between the number of statements the different age groups generated when asked to describe the film, suggesting that linguistic development may explain the findings. Few differences were found between concrete and formal operational children, which the authors took to indicate that "viewers do not on their own attribute complex psychological qualities to television characters" (Bearison et al., 1982). The argument that viewers, even very young viewers, do not automatically attribute psychological qualities to television characters seems highly unlikely given the depth of the discussions that they have at school about real and fictional people on television. It may be that characters on television spring to life only when viewers compare notes-otherwise, they remain twodimensional images on a screen. The solitary viewer needs the assurance that he or she is not being overly fanciful in making these attributions to mere television images, so when two people meet up and discuss the motives of a soap character they are effectively promoting that character to the status of a real person. Nevertheless, in a study by Babrow et al. (1988), children actually produced more abstract psychological descriptions of child characters on television than of their own peers, although the overall number of concrete behavioural attributes was greater for real children. One explanation for this finding on soaps and "reality TV" later in the book, is that television provides viewers with unique insights into aspects of human character that remain inaccessible in real life. A character in a drama (think of Hamlet, even) is depicted in solitude, articulating his or her own private thoughts, revealing "true" motives for his or her behaviour. Indeed these motives are sewn neatly into the plot-for example, in a "whodunnit" mystery, we treat each utterance as significant, and skilled writing binds these motives into explanations for the behaviour.

\section{PARENTAL MEDIATION}

Media "messages" are misinterpreted by audiences - or, at least, not interpreted the way their producers intended. Although it may be hard to force adult audiences to interpret material that challenges pre-existing attitudes and beliefs, children's understanding of media may be shaped strongly by the surrounding social context. If a parent is on hand to explain some of the more difficult or disturbing scenes a child witnesses on television or video, this may help blunt any negative effects that occur during lone viewing. A growing body of literature on the topic of "parental mediation" has examined this parental contribution to children's media use. What does parental mediation consist of? At its simplest, the parent is a co-viewer; this is a contrast with the feared image of TV-as-babysitter, in which - at least in popular lore - the parent dumps the child in front of the set in order to be free to carry out household chores and other activities undisturbed. The concern here is that the child is left vulnerable to the unmediated of violence, sex, aggression, and other undesirable material, and after a certain age may be competent enough to actively select and operate "video nastiest" left unattended on the shelf by the negligent parent. When the adult views television with the child, there is an opportunity to discuss and
(C) 2014 www.ijip.in
July-September 2014
$132 \mid \mathrm{P}$ a g e 
explain some of the more disturbing material, and to consolidate the pro-social or educational content.

How far should we be concerned about children's lone television use? A study by St. Peters, Fitch, Huston, Wright, and Eakins (1991) found that children below the age of seven watched around $75 \%$ of children's television by themselves, but this figure was notably lower for comedy, drama news, and sport programmes. Ironically, given the "video nasty" fears, children are much more likely to view adult material when co-viewing with an adult; in other words, it is the adults who make the decisions about viewing material. However, it might be that co-viewing tends to be incidental (e.g., children being allowed to stay up late especially to watch an adult programme with their parents). Of course, the view of many parents is that the only way to prevent children from watching undesirable media is simply to prohibit viewing. St. Peters et al. found that, in their sample, restricted viewers generally saw less of everything - in other words, rather than controlling the quality of television their children watch, restrictive parents simply control the quantity ("One hour and no more!") There are several problems with blanket restrictions on viewing: Policing exposure to undesirable media is virtually impossible; even if preschool children can be protected from it, they are likely to find out eventually; and the "forbidden fruit" effect may be stronger for children whose media use is subject to such censure. Nevertheless, a 1988 Gallup poll in the United States found that adults were seven times more likely to change channel, or forbid viewing, rather than discuss undesirable content (Austin, 1993).

The significance of mediation was realised by the early creators of children's media at the BBC, where the radio schedule was entitled Listen with Mother and the corresponding television schedule watch with Mother. The pattern of contemporary domestic media use is vastly different, of course, with so many young children owning their own television sets, and having the ability to operate video playback. Therefore, the need for parents and children to share viewing experiences assumes greater importance than in the past. Nor is simple co-viewing the answer; Austin (1993) argued that effective mediation requires parents to discuss the programme content with the child, perhaps explain ambiguous or disturbing material, or follow up on concepts from the viewing session.

Not only might there be different styles of mediation for different material, but there may be differences between the mediators themselves. Valkenburg, Krcmar, Peeters, and Marseille (1999) identified three different mediation styles among parents: social co-viewing, when parents and children watch together but do not discuss content; restrictive mediation, when parents prohibit watching certain material; and instructive mediation, which involves discussion and explanation. It could be argued that only the third style qualifies as mediation in the classic sense because, as Austin (1993) argued, simple co-viewing and prohibitive viewing are largely ineffective means of modifying children's interpretation of television. Austin, Bolls, Fujioka, and Engelbertson (1999) examined mediation in more depth in a telephone survey with 255 adults, and identified four mediation styles. Non-mediators are parents who might co-view with children but never discuss content. Optimists are those whose mediation consists of mostly positive comments about the content, and who tend to be generally trusting of television (even using it as a "babysitter"). Pessimists make generally negative or sceptical comments to their children, and tend to be generally distrustful of television, watching less prime-time material. Selective are mediators with a more or less equal balance of negative and positive contributions. The nature of parent-child discussions about television are therefore likely to rely heavily on parental attitudes toward the media. They are also likely to rely on existing communication patterns within
(C) 2014 www.ijip.in
July-September 2014
133 | P a g e 
families and on general parenting style (Gunter \& McAleer, 1997). Furthermore, we need to appreciate that adults may fail to pick up on the salience of much media content, particularly prosocial material. "Pessimists" may moderate the effects of media violence on their children but fail to compensate by not reinforcing pro-social messages. Parents play importance role in Development of Children's Understanding of the Fantasy-Reality Distinction in Television.

\section{Conclusion:}

Media has concerned the impact of televised violence and violence contained within video games on children and concluded that exposure to Media and video game violence leads to increased aggression, an effect that has been demonstrated both as a short term consequence and longer-term effect of excessive exposure. Parents commonly express concern over advertising directed at children, perceiving it as a source of conflict with their children who demand advertised products that parents may feel are inappropriate, and also fearing that it may lead them to adopt overly materialistic values. Media play Importance role in child socialization processes and it play role to teach child cultural values and beliefs. Media also play role in Children education and their awareness about Global issues. Parental Mediation play Importance role to Increase Positive effect of media on children and reduce Negative effect of Media on children.

\section{REFERENCES:}

1. Anderson, C. A., Shibuya, A., Ihori, N., Swing, E. L., Bushman, B. J., Sakamoto, A., \& Saleem, M. (2010). Violent video game effects on aggression, empathy, and prosocial behavior in Eastern and Western countries. Psychological Bulletin, 136, 151-173.

2. Anderson, C. A., \& Bushman, B. (2002). Human aggression. Annual Review of Psychology, 53, 27-51.

3. Austin, E. W. (1993). Exploring the effects of active parental mediation of television content. Journal of Broadcasting and Electronic Media, 37, 147-158.

4. Austin, E. W., Bolls, P., Fujioka, Y., \& Engelbertson, J. (1999). How and why parents take on the tube. Journal of Broadcasting and Electronic Media, 43, 175-192.

5. Babrow, A. S., O’Keefe, B. J., Swanson, D. L., Meyers, R. A., \& Murphy, M. A. (1988). Person perception and children's impressions of television and real peers. Communication Research, 15, 680-698.

6. Australian Psychological Psychology. (2013). Media Representations and Responsibilities: Psychological Perspectives. Melbourne: Collins Street VIC 3000.

7. Bandura, A. (1973). Aggression: A social learning analysis. Englewood Cliffs, NJ: Prentice-Hall.

8. Bandura, A. (2001). Social cognitive theory of mass communication. Media Psychology, 3, 265-299. 
9. Bandura, A., Ross, D., \& Ross, S. A. (1963). Imitation of film-mediated aggressive models. Journal of Abnormal and Social Psychology, 66, 3-11.

10. Bearison, D. J., Bain, J. M., \& Daniele, R. (1982). Developmental changes in how children understand television. Social Behavior and Personality, 10, 133-144.

11. Bretherton, I., \& Beeghly, M. (1982). Talking about internal states: The acquisition of an explicit theory of mind. Developmental Psychology, 18, 906-921.

12. Buller, D. B., Borland, R., \& Burgoon, M. (1998). Impact of behavioral intention on effectiveness of message features: Evidence from the Family Sun Safety Project. Health Communication, 24, 433-453.

13. Cantor, N. (1994). Fright reactions to mass media. In J. Bryant \& D. Zillman (Eds.), Media effects: Advances in theory and research (pp. 213-246). Hillsdale, NJ: Lawrence Erlbaum.

14. Comstock, G., \& Scharrer, E. (1999). Television: What's on, who's watching, and what it means. San Diego, CA: Academic.

15. David, G.,(2003). Media Psychology. New Jersey London: Lawrence Erlbaum Associates.

16. Davis, M. H. (1983). Measuring individual differences in empathy: Evidence for a multidimensional approach. Journal of Personality and Social Psychology, 44, 113-126.

17. Drabman, R., \& Thomas, M. (1974). Does media violence increase children's toleration of real-life aggression? Developmental Psychology, 10, 419-421.

18. Freedman, J. L. (1986). Television and aggression: A rejoinder. Psychological Bulletin, $100,372-378$.

19. Gerbner, G., Gross, L., Morgan, M., \& Signorielli, N. (1994). Growing up with television: The cultivation perspective. In J. Bryant \& D. Zillmann (Eds.), Media effects: Advances in theory and research (pp. 17-43). Hillsdale, NJ: Lawrence Erlbaum Associates.

20. Greenfield, J. (1977). Television: The first 25 years. New York: Harry Abrams.

21. Gunter, B., \& McAleer, J. (1997). Children and television (2nd ed.). London: Routledge.

22. Hoffner, C., \& Cantor, J. (1985). Developmental differences in responses to a television character's appearance and behaviour. Developmental Psychology, 21, 1065-1074. 
23. Huesmann, L. R., \& Miller, L. (1994). Long-term effects of repeated exposure to media violence in childhood. In L. Rowell Huesmann (Ed.), Aggressive behavior: Current perspectives (pp. 153-186). New York: Plenum Press.

24. Johnson, D., Flora, J. A., \& Rimal, R. N. (1997). HIV/AIDS public service announcements around the world: A descriptive analysis. Journal of Health Communication, 2, 223-234.

25. Kim, J., \& Rubin, A.M. (1997). The variable influence of audience activity on media effects. Communication Research, 24, 107-135.

26. Korhonen, T., Uutela, A., Korhonen, H. J., \& Puska, P. (1998). Impact of mass media and interpersonal health communication on smoking cessation attempts: A study in North Karelia, 1989-1996. Journal of Health Communication, 3, 105-118.

27. Paik, H., \& Comstock, G. (1994). The effects of television violence on antisocial behaviour: A meta-analysis. Communication Research, 21, 516-546.

28. Piaget, J., \& Inhelder, B. (1969). The psychology of the child. New York: Basic.

29. Reeves, B., \& Greenberg, B. (1977). Children's perceptions of television characters. Human Communication Research, 3, 113-117.

30. Reeves, B., \& Lometti, G. (1979). The dimensional structure of children's perceptions of television characters: A replication. Human Communication Research, 5, 247-256.

31. Sherry, J. L. (1998). Prosocial soap operas for development: A review of research and theory. Journal of International Communication, 48, 75-101.

32. Signorielli, N., \& Morgan, M. (Eds.). (1990). Cultivation analysis: New directions in media effects research. New York: Sage.

33. Singhal, A., \& Rogers, E. M. (1999). Entertainment-education: A communication strategy for social change. Mahwah, NJ: Lawrence Erlbaum Associates.

34. St. Peters, M., Fitch, M., Huston, A. C., Wright, J. C., \& Eakins, D. J. (1991). Television and families: What do young children watch with their parents? Child Development, 62, $1409-1423$.

35. Valkenburg, P. M., Krcmar, M., Peeters, A. L., \& Marseille, N. M. (1999). Developing a scale to assess three styles of television mediation: "Instructive mediation," "Restrictive mediation," and "Social co-viewing." Journal of Broadcasting and Electronic Media, 43, $52-66$. 
36. Wiegman, O., Kuttschreuter, M., \& Baarda, B. (1992). A longitudinal study of the effects of television viewing on aggressive and prosocial behaviours. British Journal of Social Psychology, 31, 147-164.

37. Yuill, N. (1992). Children's conception of personality traits. Human Development, 35, 265-279.

38. Zillmann, D. (1971). Excitation transfer in communication-mediated aggressive behaviour. Journal of Experimental Social Psychology, 7, 419-434.

39. Zillmann, D., \& Bryant, J. (1988). Pornography's impact on sexual satisfaction. Journal of Applied Social Psychology, 18, 438-453.

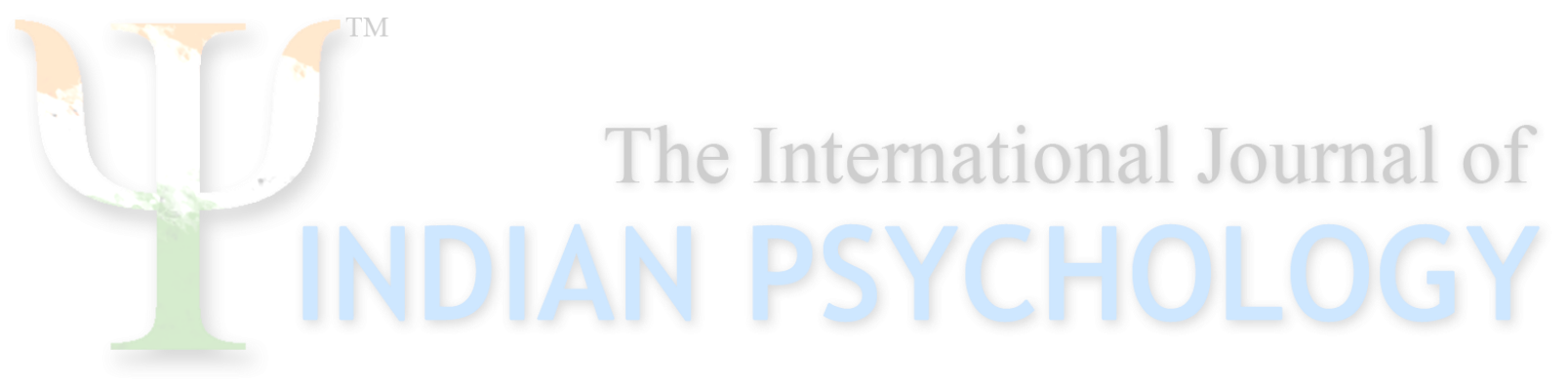

